\title{
The profile of menthol cigarette smokers in the months following the removal of these products from the market: a cross-sectional population survey in England
}

\section{Loren Kock ( $\nabla$ l.kock@ucl.ac.uk)}

University College London https://orcid.org/0000-0002-2961-8838

\section{Lion Shahab}

University College London

Ilze Bogdanovica

University of Nottingham

Jamie Brown

University College London

\section{Short Report}

Keywords: Tobacco, smoking, menthol, flavours, ban

Posted Date: August 24th, 2021

DOl: https://doi.org/10.21203/rs.3.rs-842047/v1

License: (c) (1) This work is licensed under a Creative Commons Attribution 4.0 International License.

Read Full License

Version of Record: A version of this preprint was published at Tobacco Control on November 17th, 2021. See the published version at https://doi.org/10.1136/tobaccocontrol-2021-057005. 


\section{Abstract}

Introduction

In May 2020 the EU Tobacco Products Directive ban on the sale of menthol cigarettes was implemented in England. This study examined the prevalence of menthol cigarette smoking after the ban, according to sociodemographic and smoking characteristics.

Methods

Cross-sectional data came from a representative survey of current smokers (18+) in England (unweighted $n=2,681$ ) between July/2020 and June/2021. The weighted prevalence of menthol cigarette smoking as a proportion of total cigarette smoking was calculated, log-binomial regression explored trends over time, and chi-squared statistics assessed the relationship between menthol smoking, sociodemographic and smoking characteristics. Sources of purchase of menthol cigarettes were explored.

Results

Between July 2020 and June 2021, 15.7\% (95\% Cl 14.5-17.1) of smokers reported smoking menthol cigarettes. The fitted non-linear trend supported no initial change followed by a possible reduction across April-June 2021 and fit the data better than linear and null (no change) models $(X 2(2)=2519.7, P=0.06$; $\chi 2(3)=2519.7, P=0.006)$. Menthol cigarette smoking was more common among younger groups $(16-24$ $=25.2 \% ; 25-34=19.9 \%)$ and women (19.4\%). Menthol cigarette smokers showed lower cigarette dependence compared with other smokers. Past six-month purchases of menthol cigarettes from any illicit source declined from $30.1 \%$ in the last 6 months of 2020 to $17.5 \%$ in the first 6 months of 2021 .

Conclusions

A substantial minority of current smokers in England reported menthol cigarette smoking between July/2020 and June/2021, despite the ban, possibly reflecting mitigation of restrictions by a variety of licit means, such as legal menthol accessories. The reduction in menthol smoking across April-June 2021 warrants further monitoring.

\section{What This Paper Adds}

What is already known on this subject?

- The European Union Tobacco Products Directive (TPD) ban on the sale of cigarettes with a characterising flavour was implemented in England in May 2020.

- By restricting the availability of menthol cigarettes it is hoped that the ban will reduce smoking initiation among young people and increase the overall rate of smoking cessation in the population.

- However, menthol accessories that are sold in separate packaging to tobacco or cigarettes are exempt, as are cigars, cigarillos and pipe tobacco. 
What important gaps in knowledge exist on this topic?

- This is the first study to present the profile of menthol cigarette smoking in England in a period following the EU TPD ban.

What this study adds.

- A substantial proportion of current smokers in England reported menthol cigarette smoking between July/2020 and June/2021, despite the ban.

- Menthol cigarette smokers were more likely to be younger, women and have a lower nicotine dependence profile than other smokers.

\section{Introduction}

In May 2016 the European Union Tobacco Products Directive (TPD) sales ban on cigarettes with a characterising flavour (smell or taste other than of tobacco), including menthol, was written into UK law. Following a transitional period to allow manufacturers to prepare for this ban, it was implemented in May 2020 (1). The legislation applies specifically to cigarettes and roll-your-own tobacco. Menthol accessories that are sold in separate packaging to tobacco or cigarettes are exempt, as are cigars, cigarillos and pipe tobacco.

In Europe, pre-ban data on adult smokers from several countries indicate that compared with other groups, menthol cigarette smoking prevalence was higher among younger people, women and more socio-economically advantaged (2). In England, around $12.4 \%$ of adult smokers smoked menthol cigarettes (2).

Mentholated cigarettes are associated with increased dependence and progression to regular cigarette smoking, and lower likelihood of smoking cessation $(3,4)$. By restricting their availability, it is hoped that the menthol ban will reduce smoking initiation (5) and increase the overall population smoking cessation rate. However, tobacco companies have exploited exemptions from the legislation by developing menthol filter tips for roll-your-own tobacco, flavour cards that can be inserted into packs of factory-made cigarettes or roll-your-own tobacco(1), and low-level menthol cigarettes (6).

Using data collected following implementation of the cigarette flavour ban in England, this study addressed the following research questions among current smokers:

1. What was the proportion of menthol cigarette use between July 2020-June 2021, and did it vary over the time-period?

2. What were the sociodemographic and smoking and quitting characteristics (dependence and motivation to stop smoking) of menthol cigarette smokers?

3. What were the sources of purchase of menthol cigarettes and did this change over the time-period? 


\section{Methods}

\section{Study design and participants}

Data come from adults ( $\geq 18$ years) in the Smoking Toolkit Study (STS), collected between July 2020 (the first month in which questions on menthol cigarettes were added to the STS following the TPD ban) and June 2021. The STS is a monthly repeated cross-sectional survey of a representative sample of 1,700 adults in England. Further details on the STS, including sampling and weighting techniques are described elsewhere (7).

\section{Measures}

Menthol cigarette smoking

Current smokers (including hand-rolled - see supplementary materials) were asked:

Cigarettes can be sold in different flavours. They can also be flavoured by capsules, filter tips, cards inserted into a packet or flavoured rolling papers. How would you describe the flavour of the cigarettes you usually smoke?

1. Just tobacco

2. Tobacco and menthol

3. Tobacco and some other flavour

4. Refused

5. Don't know

Answers of 2) were categorised as menthol cigarette smoking, responses of 3) were categorised as other flavour smoking. Those responding with 4) and 5) were excluded (1.3\%).

Smoking characteristics

Motivation to stop smoking was assessed using the Motivation To Stop Scale (8) and cigarette dependence questions from the Heaviness of Smoking Index (9) (see supplementary material).

Socio-demographic covariates

The sociodemographic characteristics gender, occupational social grade and ethnicity were included (see supplementary materials).

Source of purchase

Data on the source of purchase of menthol cigarettes in the past six months were also collected (see supplementary materials)

\section{Analysis}


The weighted proportion of menthol cigarette use was calculated each month according to smoking and socio-demographic characteristics. Chi-squared statistics were used to describe the strength of the relationship between menthol cigarette smoking status and the specified variables. Cramer's $V$ was used as an effect size. To explore potential trends a weighted univariate log-binomial model was fitted for the proportion of smokers who smoke menthol cigarettes as a function of time (months). To allow for nonlinear trends, time was modelled using a natural cubic spline with 2 internal knots, each placed at the $33 r d$ and 66 th quantiles of the data (10). The fit of this non-linear model was compared with linear and null (no change) models, respectively.

The prevalence of each source of purchase of menthol cigarettes was summarised for July-December 2020 and January-June 2021. These months were collapsed because source of purchase data reflects self-reported purchase in the past six months, with January 2021 onwards therefore representing a retrospective period after the ban was implemented.

Missing data on variables are reported in Table S2. The STROBE reporting guideline were used in the design and reporting of this study (11).

Sensitivity analysis

To explore changes in illicit sources of purchase of menthol cigarettes, a sensitivity analysis compared illicit sources of purchase (in the past six months) during July-December 2020 and January-June 2021 (see supplementary materials).

All analyses were carried out in $\mathrm{R}$ version 4.0.3.

\section{Results}

A weighted total of 2,908 smokers (mean (SE) age $=42.1$ (0.34); 47\% women) completed the survey between July 2020-June 2021. Overall, $15.7 \%$ (14.5\%-17.1\%) of current smokers smoked menthol cigarettes between July 2020 to June 2021 (Fig. 1A). The fitted non-linear trend supported no change followed by a possible reduction across April-June 2021 and fit the data better than linear and null (no change) models (Fig. 1B).

\section{The profile of menthol cigarette smokers}

Among all smokers, $25.2 \%$ of $16-24$ year-olds and $19.4 \%$ women smoked menthol cigarettes. Compared with other smokers, menthol cigarette smoking was more common among younger people, women and those with professional/managerial occupations (Table S2). Menthol smokers appeared less dependent by time to first cigarette and cigarettes per day, with no difference in motivation to stop.

\section{Source of purchase}


The most popular sources of menthol cigarette purchases (not mutually exclusive) in the past six months were newsagent/off license/corner shops, supermarkets and petrol garage shops (Table S3). Sources of purchase appeared similar between July-December 2020 and January-June 2021, with the exception of declines in buying abroad $(14.2 \%$ vs $10.4 \% ; \chi 2(1)=6.67, \mathrm{P}=0.01)$ and buying from friends $(12.3 \% \mathrm{vs}$ $4.2 \% ; \chi 2(1)=8.73, P=0.005)($ Table S3).

The reports of illicit purchase of menthol cigarettes in the past six months declined from $30.1 \%$ between July-December 2020 to 17.5\% between January-June 2021 (X2(1) = 9.12, P = 0.006) (Table S4).

\section{Discussion}

The EU TPD ban on the sale of menthol cigarettes was implemented in May 2020. Between July 2020 and June 2021 a substantial minority of smokers continued to report currently smoking menthol flavoured cigarettes, with an observed reduction between April-June 2021. Further monitoring of the decline will inform whether it reflects a secular trend or natural variation.

One possible reason for this pattern in England is that smokers were buying menthol cigarettes from illicit sources. However, reported purchase from any illicit source was less common in the first 6 months of 2021 than in 2020. Moreover, the observed prevalence is not consistent with stockpiling behaviour, which would be expected to drop as personal stocks dwindle. A more likely explanation is that the survey measure assessing flavoured cigarette smoking covers tobacco accessories, including menthol flavoured capsules, filter tips, cards or flavoured rolling papers that are sold separately from cigarette packs. These accessories are exempt from the ban and were introduced and promoted to retailers in the months before implementation (12). It is likely that many smokers shifted to using these compliant products (1), which is supported by leaked industry figures that in the 12 months following the ban, Japan Tobacco International sold over 2 billion ban-compliant 'menthol replacement' cigarettes in the UK (6), and by the fact that legal sources of purchase were reported at similar levels across the study period. However, without data on the prevalence of only menthol flavour accessory use before the ban, we cannot infer whether a transition occurred or if this was a continuation of increases in the UK market share of capsule cigarettes leading up to the ban (1). Further monitoring should examine changes in the proportion of cigarettes bought by type (factory-made vs roll-your-own tobacco) and whether substitution occurred with other products such as heated-tobacco and 'cigarette-like' menthol cigarillos (13).

Regarding the sociodemographic profile of menthol smokers, our findings support evidence on the popularity of menthol cigarettes among younger age groups (14) and women (15). This pattern among women likely reflects established preferences for menthol during smoking initiation (16) and the misconception that menthol cigarettes are safer than non-menthol tobacco cigarettes (17). There is also some evidence for a genetic component influencing taste preference of menthol cigarettes among women (18).

Contrary to US evidence indicating higher dependence potential of menthol cigarettes(3)(19), our results suggest that menthol smokers were less dependent than tobacco smokers. However, given that cigarette 
dependence develops for several years, the lower dependence in our sample may reflect the younger age profile of menthol compared with just tobacco smoking (20). The divergence may also reflect different regulatory and tobacco industry contexts; e.g., targeting of more disadvantaged and dependent smokers by menthol advertising campaigns in the US (20).

Inferences from our data are limited by an absence of measures on menthol smoking before the ban was implemented. Moreover, apparent changes in the proportion of menthol cigarette smokers may reflect natural variation/seasonality. Further limitations relate to the self-reported menthol smoking and past sixmonth source of purchase, which may lack accuracy due to recall bias.

The EU TPD ban on menthol cigarettes has not led to a precipitous short-term decline in menthol smoking in England. In Canada, where a more comprehensive ban was implemented covering menthol as an ingredient in cigarettes rather than just as a characterising flavour, research has found increased probability of quitting among daily menthol vs non-menthol smokers two years following the ban (21). Further research in England is needed to examine the longer-term trends in use and the potential impact the ban has had on smoking cessation among menthol cigarette smokers.

\section{Role of funding sources}

Data collection for the Smoking and Alcohol Toolkit Studies is supported by Cancer Research UK (C1417/A22962). Authors are supported by the UK Prevention Research Partnership (MR/S037519/1), an initiative funded by UK Research and Innovation Councils, the Department of Health and Social Care (England), and the UK devolved administrations and leading health research charities. No funders had any involvement in the design of the study, the analysis or interpretation of the data, the writing of the report or the decision to submit the paper for publication.

\section{Contributors}

LK, JB and LS conceived of the study. All authors contributed to the study analysis plan. LK conducted the analysis and write up. All authors contributed to the final manuscript. LK is the guarantor of this work and, as such, had full access to all the data and take responsibility for the integrity of the data and the accuracy of the data analysis.

\section{Declarations}

\section{Conflict of interest}

Authors are members of the UK Prevention Research Partnership, an initiative funded by UK Research and Innovation Councils, the Department of Health and Social Care (England), and the UK devolved administrations and leading health research charities. JB reports receiving grants from Cancer Research UK during the conduct of the study and receiving unrestricted research funding from pharmaceutical companies who manufacture smoking cessation medications to study smoking cessation outside the submitted work. LS reports receiving honoraria for talks, receiving an unrestricted research grant and 
travel expenses to attend meetings and workshops by pharmaceutical companies that make smoking cessation products (Pfizer and Johnson \& Johnson), and acting as a paid reviewer for grant-awarding bodies and as a paid consultant for health care companies. LK and IB have no competing interests to declare.

\section{References}

1. Hiscock R, Silver K, Zatoński M, Gilmore AB. Tobacco industry tactics to circumvent and undermine the menthol cigarette ban in the UK. Tob Control [Internet]. 2020 Dec 1 [cited 2020 Dec 11];29(e1):138-42. Available from: http://tobaccocontrol.bmj.com/

2. Zatoński M, Herbeć A, Zatoński W, Przewoźniak K, Janik-Koncewicz K, Mons U, et al. Characterising smokers of menthol and flavoured cigarettes, their attitudes towards tobacco regulation, and the anticipated impact of the Tobacco Products Directive on their smoking and quitting behaviours: The EUREST-PLUS ITC Europe Surveys [Internet]. Vol. 16, Tobacco Induced Diseases. International Society for the Prevention of Tobacco Induced Diseases; 2018 [cited 2020 Dec 18]. p. 20. Available from: /pmc/articles/PMC6659514/?report = abstract

3. Mills SD, Hao Y, RibisI KM, Wiesen CA, Hassmiller Lich K. The Relationship between Menthol Cigarette Use, Smoking Cessation and Relapse: Findings from Waves 1 to 4 of the Population Assessment of Tobacco and Health Study. Nicotine Tob Res [Internet]. 2020 Oct 16 [cited 2021 Jan 14]; Available from: https://academic.oup.com/ntr/advancearticle/doi/10.1093/ntr/ntaa212/5924832

4. US Food and Drug Administration. Preliminary Scientific Evaluation of the Possible Public Health Effects of Menthol Versus Nonmenthol Cigarettes. 2013.

5. Cadham CJ, Sanchez-Romero LM, Fleischer NL, Mistry R, Hirschtick JL, Meza R, et al. The actual and anticipated effects of a menthol cigarette ban: A scoping review [Internet]. Vol. 20, BMC Public Health. BioMed Central; 2020 [cited 2020 Dec 18]. p. 1055. Available from: https://bmcpublichealth.biomedcentral.com/articles/10.1186/s12889-020-09055-z

6. Daily Express. Menthol cigarette ban "worthless" as $£ 1$ bn worth sold in year via loophole [Internet]. 2021 [cited 2021 Aug 20]. Available from: https://www.express.co.uk/news/uk/1460053/mentholcigarette-ban-New-Superking-Green-Sterling-New-Dual

7. Fidler JA, Shahab L, West O, Jarvis MJ, McEwen A, Stapleton JA, et al. "The smoking toolkit study": a national study of smoking and smoking cessation in England. BMC Public Health [Internet]. 2011 Jun 18 [cited 2017 Oct 25];11:479. Available from: http://www.ncbi.nlm.nih.gov/pubmed/21682915

8. Kotz D, Brown J, West R. Predictive validity of the Motivation To Stop Scale (MTSS): a single-item measure of motivation to stop smoking. Drug Alcohol Depend. 2013;128(1-2):15-9.

9. HEATHERTON TF, KOZLOWSKI LT, FRECKER RC, RICKERT W, ROBINSON J. Measuring the Heaviness of Smoking: using self-reported time to the first cigarette of the day and number of cigarettes smoked per day. Addiction [Internet]. 1989 Jul 1 [cited 2018 Nov 15];84(7):791-800. Available from: http://doi.wiley.com/10.1111/j.1360-0443.1989.tb03059.x 
10. Harrell FE. Regression modeling strategies: with applications to linear models, logistic and ordinal regression, and survival analysis. Vol. 3. Springer; 2015.

11. Knottnerus A, Tugwell P. STROBE-a checklist to Strengthen the Reporting of Observational Studies in Epidemiology. J Clin Epidemiol. 2008;61(4):323.

12. Dance S, Evans-Reeves K. Menthol: Tobacco Companies are exploiting loopholes in the UK's characterising flavours ban. Tob Control. 2021;

13. Branston JR, Hiscock R, Silver K, Arnott D, Gilmore AB. Cigarette-like cigarillo introduced to bypass taxation, standardised packaging, minimum pack sizes, and menthol ban in the UK. Tob Control. 2020;

14. Cohn AM, Rose SW, D'Silva J, Villanti AC. Menthol smoking patterns and smoking perceptions among youth: findings from the population assessment of tobacco and health study. Am J Prev Med. 2019;56(4):e107-16.

15. Smith PH, Akpara E, Haq R, El-Miniawi M, Thompson AB. Gender and Menthol Cigarette Use in the USA: A Systematic Review of the Recent Literature (2011-May 2017) [Internet]. Vol. 4, Current Addiction Reports. Springer; 2017 [cited 2021 Feb 19]. p. 431-8. Available from: /pmc/articles/PMC5826627/

16. Kasza KA, Hyland AJ, Bansal-Travers M, Vogl LM, Chen J, Evans SE, et al. Switching between menthol and nonmenthol cigarettes: findings from the US Cohort of the International Tobacco Control Four Country Survey. nicotine Tob Res. 2014;16(9):1255-65.

17. Moodie C, Ford A, Mackintosh A, Purves R. Are all cigarettes just the same? Female's perceptions of slim, coloured, aromatized and capsule cigarettes. Health Educ Res. 2015;30(1):1-12.

18. Oncken C, Feinn R, Covault J, Duffy V, Dornelas E, Kranzler HR, et al. Genetic vulnerability to menthol cigarette preference in women. Nicotine Tob Res. 2015;17(12):1416-20.

19. Benowitz NL, Herrera B, Jacob P. Mentholated cigarette smoking inhibits nicotine metabolism. J Pharmacol Exp Ther. 2004;310(3):1208-15.

20. Villanti AC, Collins LK, Niaura RS, Gagosian SY, Abrams DB. Menthol cigarettes and the public health standard: a systematic review. BMC Public Health. 2017;17(1):1-13.

21. Chaiton M, Schwartz R, Cohen JE, Soule E, Zhang B, Eissenberg T. Prior daily menthol smokers more likely to quit two years after a menthol ban than non-menthol smokers: a population cohort study. Nicotine Tob Res. 2021;

\section{Figures}



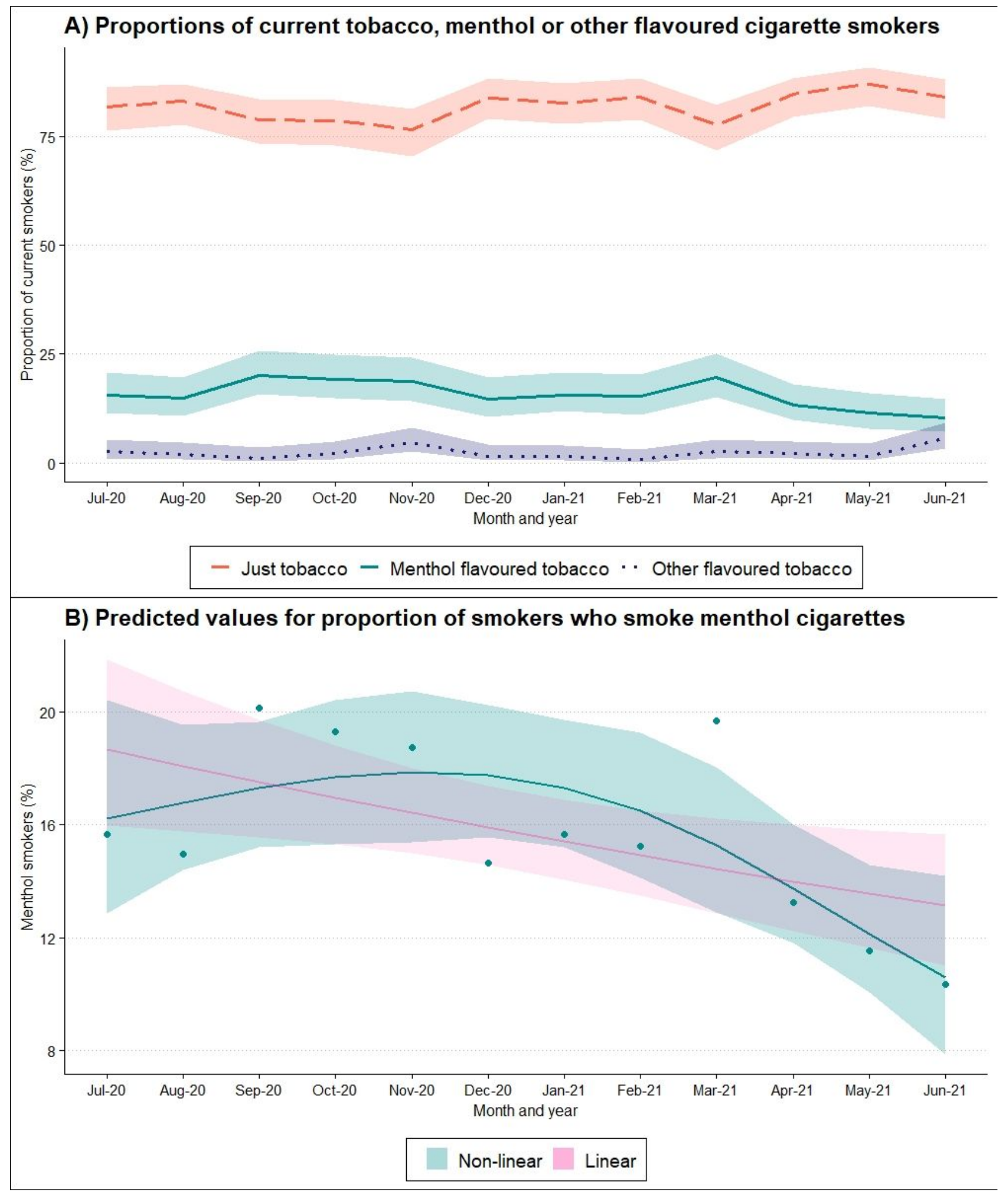

\section{Figure 1}

A) Proportion of smokers who smoke just tobacco, tobacco and menthol or tobacco and other flavour cigarettes and B) fitted non-linear and linear trends in the proportion of menthol cigarette smokers between July 2020 and June 2021 Data from the Smoking Toolkit Study, University College London. Unweighted $n=2,681$. Shaded bands represent $95 \% \mathrm{Cls}$; A) Data are weighted to match the sociodemographic profile of adults in England; B) Fitted log-binomial regression of weighted proportion of 
smokers who smoke menthol cigarettes as a function of survey wave. To allow for non-linear trends, year was modelled using a natural cubic spline with 2 knots, each placed at equally-spaced quantiles of the data(10). Results of likelihood ratio test indicated the spline model was a better fit of the data than linear $(X 2(2)=2519.7, P=0.06)$ and null (intercept only) models $(X 2(3)=2519.7, P=0.006)$ respectively. Points on graph indicate weighted proportion of smokers who use menthol cigarettes.

\section{Supplementary Files}

This is a list of supplementary files associated with this preprint. Click to download.

- Supplementarymaterials0.3.docx 